\title{
The Effect of Supplemental Blue, Red and Far-Red Light on the Growth and the Nutritional Quality of Red and Green Leaf Lettuce
}

\author{
Myungjin Lee1, Jingwen $\mathrm{Xu}^{2}$, Weiqun Wang², C. B. Rajashekar ${ }^{1 *}$ \\ ${ }^{1}$ Department of Horticulture and Natural Resources, Kansas State University, Manhattan, KS, USA \\ ${ }^{2}$ Department of Food, Nutrition, Dietetics and Health, Kansas State University, Manhattan, KS, USA \\ Email: ${ }^{\star}$ crajashe@ksu.edu
}

How to cite this paper: Lee, M., Xu, J.W., Wang, W.Q. and Rajashekar, C.B. (2019) The Effect of Supplemental Blue, Red and Far-Red Light on the Growth and the Nutritional Quality of Red and Green Leaf Lettuce. American Journal of Plant Sciences, 10, 2219-2235.

https://doi.org/10.4236/ajps.2019.1012157

Received: November 27, 2019

Accepted: December 22, 2019

Published: December 25, 2019

Copyright $\odot 2019$ by author(s) and Scientific Research Publishing Inc. This work is licensed under the Creative Commons Attribution International License (CC BY 4.0).

http://creativecommons.org/licenses/by/4.0/

\begin{abstract}
Spectral quality of radiation has a major impact on the growth, development and nutritional quality of crops. The effect of supplemental radiation (blue, red and far-red) on the growth and nutritional quality with regard to health-promoting phytochemical and micronutrient composition of two lettuce (Lactuca sativa) varieties (red leaf "New Red Fire" and green leaf "Two Star") was studied. Supplemental radiation was provided by blue $(450 \mathrm{~nm})$, red $(660 \mathrm{~nm})$ or far-red $(730 \mathrm{~nm})$ LEDs against a background of white light (fluorescent lighting, PAR; $270 \mu \mathrm{mol} / \mathrm{m}^{2} / \mathrm{s}$ ) in a growth chamber study. All the supplemental radiation treatments increased dry shoot biomass in both varieties. However, supplemental far-red radiation increased both fresh and dry shoot biomass in both varieties. In addition, supplemental far-red radiation produced distinct morphological characteristics in lettuce plants. It produced the largest shoot biomass, bigger and taller plants, fewer leaves but with larger leaf area compared to the control, similar to the shade avoidance response. With regard to the accumulation of phytochemicals, supplemental blue radiation enhanced the total phenolic compound concentration in both varieties. In addition, supplemental blue radiation sharply increased the accumulation of several phenolic compounds in green leaf lettuce including chlorogenic acid, chicoric acid, rutin, kaempferol, luteolin and apigenin. For example, the leaf concentration of rutin in green leaf lettuce increased by 20 -fold under supplemental blue radiation. Similarly, supplemental red radiation increased the concentration of many of these phenolic compounds in red leaf lettuce. However, supplemental far-red radiation had an inhibitory effect on the accumulation of chlorogenic acid, chicoric acid, rutin and kaempferol
\end{abstract}


in red leaf lettuce. While supplemental radiation did not affect the accumulation of most of the micronutrients, it had a negative impact on the accumulation of some micronutrients, the response being variety dependent. The results show that supplementing white light with specific spectral quality has a major impact on the biomass accumulation, morphology and on the accumulation of many health-promoting phytochemicals and micronutrients in lettuce. While it had a large positive effect in enhancing the accumulation of several phytochemicals, it also suppressed the accumulation of some micronutrients.

\section{Keywords}

LEDs, Lettuce, Micronutrients, Nutritional Quality, Phytochemicals, Spectral Quality

\section{Introduction}

Light plays a vital role not only in many aspects of plant growth and development including seed germination, shoot and leaf growth, dormancy and flowering but also in the primary and secondary metabolism thus affecting the nutritional quality of plants [1] [2] [3] [4]. Light intensity, spectral quality and duration of exposure to light (photoperiod) play a key role in photo-responses of plants. Manipulation of above light factors, especially spectral quality, provides a potential opportunity to enhance growth, control development and improve nutritional quality and aesthetic appeal of crops, which can enhance their marketability [5]-[10]. Photosynthetic function is among many factors that contribute directly to growth and biomass accumulation in plants, and blue and red radiation of the visible spectrum play an important direct role in this as they provide the energy needed for carbon assimilation. In addition to this, both blue and red radiation also regulate many aspects of morphogenesis including shoot elongation, cell differentiation, modulating shoot growth and flower initiation and also, numerous biochemical and physiological processes including those involved in secondary metabolism [8] [11]. Thus, notably spectral characteristics of light have a significant impact on the nutritional quality of plants including on the accumulation of health-promoting phytochemicals such as phenolic compounds, carotenoids, glucosinolates and micronutrients [7] [12] [13] [14].

Increasing number of food crops, especially horticultural food crops, are now being produced under environmentally controlled conditions using artificial source of lighting especially light emitting diodes (LEDs) [8]. The emerging LED technology has made it possible to use narrow band of light spectra to control growth, flowering and nutritional quality of crops [3] [5] [6]. LEDs emitting red and blue radiations are commonly used to grow a number of crop plants in controlled environment conditions as they provide photosynthetically active radiation [15]. However, in recent years, green and far-red have also been added to the mix to modify plant growth and morphology in leafy vegetables [5] [16] [17]. 
The primary photoreceptors that are responsible for morphogenic responses in plants that allow the plants to sense and adapt to the quality, intensity and duration of light are red/far-red absorbing phytochromes and blue absorbing phototropins and cryptochromes [18] [19]. Phytochromes are chromoproteins containing 2 polypeptide subunits with a covalently-bound tetrapyrrole (billin) chromophore sensitive to red and far-red light. There are two interconvertible forms of phytochromes, Pr and Pfr. Pr form absorbs red light and is converted into Pfr form which can be rapidly converted back to Pr form by absorbing far-red light. Interestingly, the absorption spectra of Pr and Pfr somewhat overlap and thus, there is a balance between these two forms of phytochromes. This helps the photoreceptor molecule to actually sense the quality of light that surrounds the plants, which in turn will allow for a greater control on the physiological processes and plant responses such as seed germination, photomorphogenesis, shade avoidance and photoperiod dependent responses [20]. The Pfr form of phytochrome produced in the presence of red light is considered as the physiologically active form, which can modulate many plant functions while far-red light can produce Pr form of phytochrome and has been linked to enhanced plant growth and shade avoidance strategies [21] [22] [23].

Blue light, in addition to its important role in photosynthesis, is also involved in morphogenic responses such as phototropism, suppression of stem elongation and stomatal regulation [19]. There are two types photoreceptors of blue radiation namely, phototropins and cryptochromes. Phototropins are flavoproteins which mediate phototropic responses in plants i.e., directional movement of plant organs toward light, control of stomatal opening and chloroplast movement. Cryptochromes are photolyase-like flavoproteins sensitive to blue light and are involved in photomorphogenic responses such as photoperiod controlled flowering, inhibition of hypocotyl elongation, stomatal opening, root development, apical dominance, light dependent gene expression and regulation of many physiological and biochemical processes [24] [25].

In a previous study, we found that environmental conditions have a notable impact on the secondary metabolism resulting in a significant accumulation many important health-promoting phytochemicals in lettuce [26]. High light intensity increased the accumulation of total phenolic compounds in the leaves by 3 -fold compared to the control plants along with significant increases in chlorogenic acid, caffeic acid, chicoric acid, quercetin-3-O-glucoside and luteolin-7-O-glucodise. In addition, light elicits much stronger phytochemical response in lettuce than other environmental factors such as low or high temperatures. Previous studies have examined the spectral quality of light on plant growth and development and nutritional quality of plants including leafy vegetables using narrow-band LEDs. Often LEDs with different spectral outputs in various combinations (red, blue and green) have been used to study plant responses, an approach to identify the best combination of spectral quality that can produce the desired impact on plants [16]. However, this approach does not lend itself to discern effects of a specific spectral quality of light on plant func- 
tions. Therefore, in lieu of combination of spectral bands of radiation, in the current study we supplement traditional source of PAR (white light) with specific spectral quality in order to identify its impact on plant responses. The objective of this study was to examine the impact of supplementing traditional white light (PAR) with red, blue or far-red radiation in order to evaluate the growth and the nutritional quality with regard to the accumulation of health-promoting phytochemicals and micronutrients in red and green leaf lettuce varieties.

\section{Materials and Methods}

\subsection{Plant Materials and Growing Conditions}

Seeds of two varieties of lettuce (Lactuca sativa), a red leaf "New Red Fire" and a green leaf "Two Star" were sown in a commercial soil mix (Metromix 360, Sungro Horticulture, Agawam, MA) contained in seedling trays and the seedlings were grown for 2 weeks in a growth chamber set at $22^{\circ} \mathrm{C}$ (day/night) under fluorescent lamp (white light) with a photon flux of $300 \mu \mathrm{mol} / \mathrm{m}^{2} / \mathrm{s}$ and a $12 \mathrm{~h}$ photoperiod. The seedlings were then transplanted into pots $(12 \mathrm{~cm} \times 12 \mathrm{~cm} \times$ $12 \mathrm{~cm}$ ) with the same soil mix as above and were subsequently transferred to a large growth chamber containing 3 open-top chambers $(66 \mathrm{~cm}$ width $\times 56 \mathrm{~cm}$ depth $\times 77 \mathrm{~cm}$ height), each constructed out of white reflective particle boards. The chambers were used for supplementing the background white light (fluorescent lamps) with blue, red, or far-red radiation by using LED arrays. The growing conditions were $22^{\circ} \mathrm{C}$ (day/night) and $60 \%$ relative humidity with a photon flux for the background light (PAR) of $270 \mu \mathrm{mol} / \mathrm{m}^{2} / \mathrm{s}$ and a $12 \mathrm{~h}$ photoperiod. The LED arrays consisted of LED bars $(47 \mathrm{~cm}$ long) mounted vertically $16 \mathrm{~cm}$ apart along the walls of the open-top chambers. Each open-top chamber contained blue (peak $450 \mathrm{~nm}$ ), red (peak $660 \mathrm{~nm}$ ) or far-red (peak $730 \mathrm{~nm}$ ) LEDs (Philips GreenPower Research Module; 24 V/10 - 15 W) and each LED bar had a photon flux output in the range of $13-16 \mu \mathrm{mol} / \mathrm{s}$ as supplemental source of lighting. The supplemental photon flux output in each open-top chamber was in the range of $78-96 \mu \mathrm{mol} / \mathrm{s}$. Fluorescent background lighting without the LEDs represented the control.

Supplemental LED treatments were started when seedlings were 2 weeks old. Each LED treatment and the control had 4 replications and the experiment was laid out on a completely randomized design. Pots in each chamber were randomly rearranged in each open-top chamber every 2 days to minimize the uneven exposure of plants to supplemental radiation. Plants were watered every 2 days and fertilized once a week with irrigation water (N:P:K; 20:10:20) at 200 ppm of N.

All the growth characteristics were measured at the time of harvest (4 weeks after transplanting). The fresh biomass of shoots and roots was measured and their dry biomass was obtained after drying them at $75^{\circ} \mathrm{C}$ in an oven for $72 \mathrm{~h}$. In addition, leaf number/plant was recorded. Leaf area was measured using a 
LI-3100 Area Meter (LI-COR, Inc., Lincoln, Nebraska). As the lettuce varieties used in this study are loose leaf type, the plant height was measured from the base of the plant to include the longest leaf in the canopy. Photosynthetic photon flux density (PPFD) was measured using a quantum radiometer (LI-185B, LI-Cor, Inc., Lincoln, NE). The PPFD measurements were made at the canopy level and the mean PPFD was obtained from 9 measurements made within each open-top chamber.

\subsection{Chlorophyll and Carotenoid Measurements}

Four lettuce plants from each treatment were randomly selected to determine the chlorophyll and carotenoid concentrations in their leaves. The freeze-dried leaf sample $(0.3 \mathrm{~g})$ was extracted with $3 \mathrm{~mL} 80 \%$ acetone for $25 \mathrm{~min}$ in an ultrasonic processor (Vibra-Cell, Sonics and Materials Inc., Danbury, CT). The absorbance (A) of the extracts was read at $663 \mathrm{~nm}, 645 \mathrm{~nm}$ and $470 \mathrm{~nm}$ in a microplate reader (Synergy H1, BioTek, Winooski, VT). The leaf concentrations of chlorophyll a (Chl a), chlorophyll b ( $\mathrm{Chl} \mathrm{b)}$ and carotenoids were estimated according to the methods by Chen et al. [27] with some modifications using the following relationships:

$$
\begin{gathered}
\text { Chl a }=12.72 \mathrm{~A}_{663}-2.59 \mathrm{~A}_{645} \\
\mathrm{Chl} \mathrm{b}=22.88 \mathrm{~A}_{645}-4.567 \mathrm{~A}_{663} \\
\text { Total Chl a }+\mathrm{b}=20.3 \mathrm{~A}_{645}+7.22 \mathrm{~A}_{663} \\
\text { Carotenoids }=\left(1000 \mathrm{~A}_{470}-3.27 \mathrm{Chl} \mathrm{a}-104 \mathrm{Chl} \mathrm{b}\right) / 229
\end{gathered}
$$

\subsection{Total Phenolic Compounds and Antioxidant Capacity}

Total phenolic compounds were extracted according to Oh et al. [26] using the modified Folin-Ciocalteu reagent method [28]. Leaf sample (4 replications/ treatment, $0.04 \mathrm{~g}$ each) was used to extract in $4 \mathrm{~mL}$ of $80 \%$ acetone using an ultrasonic processor (Vibra-Cell, Sonics and Materials, Inc., Danbury, CT) for 20 min and then $1.5 \mathrm{~mL}$ of the sample was transferred to a centrifuge tube and kept in the darkness overnight at $4^{\circ} \mathrm{C}$. The extract was than centrifuged at $1000 \mathrm{rpm}$ for 2 min and a $50 \mu \mathrm{L}$ of the supernatant was mixed with $135 \mu \mathrm{L}$ of distilled water, $750 \mu \mathrm{L}$ diluted (1:10) Folin-Ciocalteu reagent (Sigma-Aldrich, St. Louis, MO, USA) and $600 \mu \mathrm{L}$ of $7.5 \%(\mathrm{w} / \mathrm{v}) \mathrm{Na}_{2} \mathrm{CO}_{3}$. The mixture was vortexed and incubated in a water bath at $45^{\circ} \mathrm{C}$ for $15 \mathrm{~min}$ and was then allowed to cool at room temperature. Absorbance was read at $765 \mathrm{~nm}$ (U-1100 Spectrophotometer, Hitachi Ltd. Japan). Gallic acid standards were made from freshly prepared gallic acid (Acros Organics, Belgium) in $80 \%$ acetone with 3 replicates for each concentration.

Total Antioxidant capacity was measured using ABTS decolorization assay as outlined by Miller and Rice-Evans [29] and Pennycooke et al. [30]. A $2.5 \mathrm{mM}$ ABTS stock solution was prepared in $20 \mathrm{~mL}$ distilled water and the ABTS * radical cations were generated by adding $0.4 \mathrm{~g}$ of $\mathrm{MnO}_{2}$ as an oxidizing agent to 
ABTS solution and stirring continuously at room temperature. Excess $\mathrm{MnO}_{2}$ was removed by filtering under vacuum first, and then using $0.22 \mu \mathrm{m}$ syringe end filter (MilliporeSigma, Burlington, MA). Then the ABTS* solution was diluted to an absorbance value of $0.7( \pm 0.05)$ at $730 \mathrm{~nm}$ by using $5 \mathrm{mM}$ PBS (phosphate buffer saline) at $\mathrm{pH} 7.4$ and stored in water bath at $30^{\circ} \mathrm{C}$. Trolox standards were prepared from a stock solution of $0.5 \mathrm{mM}$ trolox. One $\mathrm{mL}$ of ABTS* reagent was added to trolox standards or samples and vortexed for $10 \mathrm{~s}$ and followed by 1 min of reaction time. The absorbance of the reaction mixture was measured at $730 \mathrm{~nm}$. A PBS solution was used as a blank for each assay. The antioxidant capacity of samples was estimated as the trolox equivalent.

\subsection{Individual Phenolic Compounds and Quantification}

Freeze-dried and ground leaf samples $(0.15 \mathrm{~g})$ were extracted overnight with 15 $\mathrm{mL}$ of $70 \%$ aqueous methanol containing flavone as an internal standard on an orbital shaker (Benchmark, Edison, NJ). The extract was centrifuged and filtered 3 times to remove cell debris. Aqueous methanol was added to make up the final volume $(25 \mathrm{~mL})$ and $2 \mu \mathrm{L}$ of this was evaporated to dryness under streaming nitrogen gas. The residue was re-dissolved in $1 \mathrm{~mL}$ of $70 \%$ methanol and then filtered through $0.22 \mu \mathrm{m}$ syringe end filter (MilliporeSigma, Burlington, MA). The phenolic compounds were quantified using a Shimadzu HPLC system (Kyoto, Japan) consisting of a DGU-20A3 degasser, a LC-20AB liquid delivery pump, a SIL-20ACHT auto-sampler, a CTO-20AC column oven and a SPD-20A diode array detector. A C18 reversed phase column $(250 \mathrm{~mm} \mathrm{~L} \times 4.6 \mathrm{~mm} \mathrm{D}$, Waters, Milford, MA) was used to separate the phenolic compounds. The elution was conducted with a mobile phase A consisting of 5\% formic acid in deionized water and mobile phase B consisting of 5\% formic acids in $95 \%$ methanol at a rate of $0.8 \mathrm{~mL} / \mathrm{min}$ and $31^{\circ} \mathrm{C}$ oven temperature. The gradient used for solvent $\mathrm{B}$ was 0 - 10\% for $5 \mathrm{~min}, 10 \%$ - 40\% for $25 \mathrm{~min}, 40 \%$ - 70\% for $10 \mathrm{~min}$, and $70 \%$ for 16 min before returning to $0 \%$. The phenolic compounds were separated and quantified using the method described by Woolley et al. [31]. The data were analyzed using the Shimadzu LC Solution Software (Kyoto, Japan). Concentrations of phenolic acids (gallic acid, chlorogenic acid, caffeic acid and chicoric acid) and flavonoids (luteolin, apigenin, kaempferol and rutin) were expressed as equivalents of vanillic acid and quercetin, respectively.

\subsection{Micronutrient Analyses}

Leaf samples were collected at the time of harvest and were dried in an oven at $72^{\circ} \mathrm{C}$ for $72 \mathrm{~h}$. The dried samples were ground in an electric grinder and the total carbon and nitrogen concentrations in the sample were determined using a LECO TrueSpec CN combustion analyzer. The concentrations of micronutrients including phosphorus, potassium, calcium, magnesium, sulfur, copper, iron, manganese and zinc were determined using an inductively coupled plasma (ICP) spectrometer (Model 720-ES ICP Optical Emission Spectrometer, Varian, Aus- 
tralia PTY Ltd., Australia).

\subsection{Statistical Analyses}

The mean separation of treatment effects was performed using Analysis of Variance (ANOVA) (SAS 9.4, Cary, NC and XLSTAT, Addinsoft, New York, NY) and the treatment comparisons were conducted by using the Duncan's multiple range test for growth characteristics and micronutrient composition and by $\mathrm{Tu}$ key's test for phenolic compounds.

\section{Results and Discussion}

Red leaf (New Red Fire) and green leaf (Two Star) varieties of lettuce were grown in growth chambers with supplemental blue, red or far-red radiation using LEDs. Supplemental light of various spectral quality affected both shoot and root characteristics of both red and green leaf varieties of lettuce. However, the responses were variable and variety dependent. One common response of both varieties was that their exposure to far-red supplemental lighting significantly increased both fresh and dry biomass of shoots relative to control plants (W) that received fluorescent lighting with no supplemental lighting (Figure 1). However, the largest increase in shoot fresh biomass in "New Red Fire" was due to supplemental far-red radiation while such increase in "Two Star" was with supplemental red radiation compared to the control plants. These increases in shoot fresh biomass were over 70\% in "New Red Fire" and over 56\% in "Two Star" compared to the control plants. While shoot fresh biomass increased with

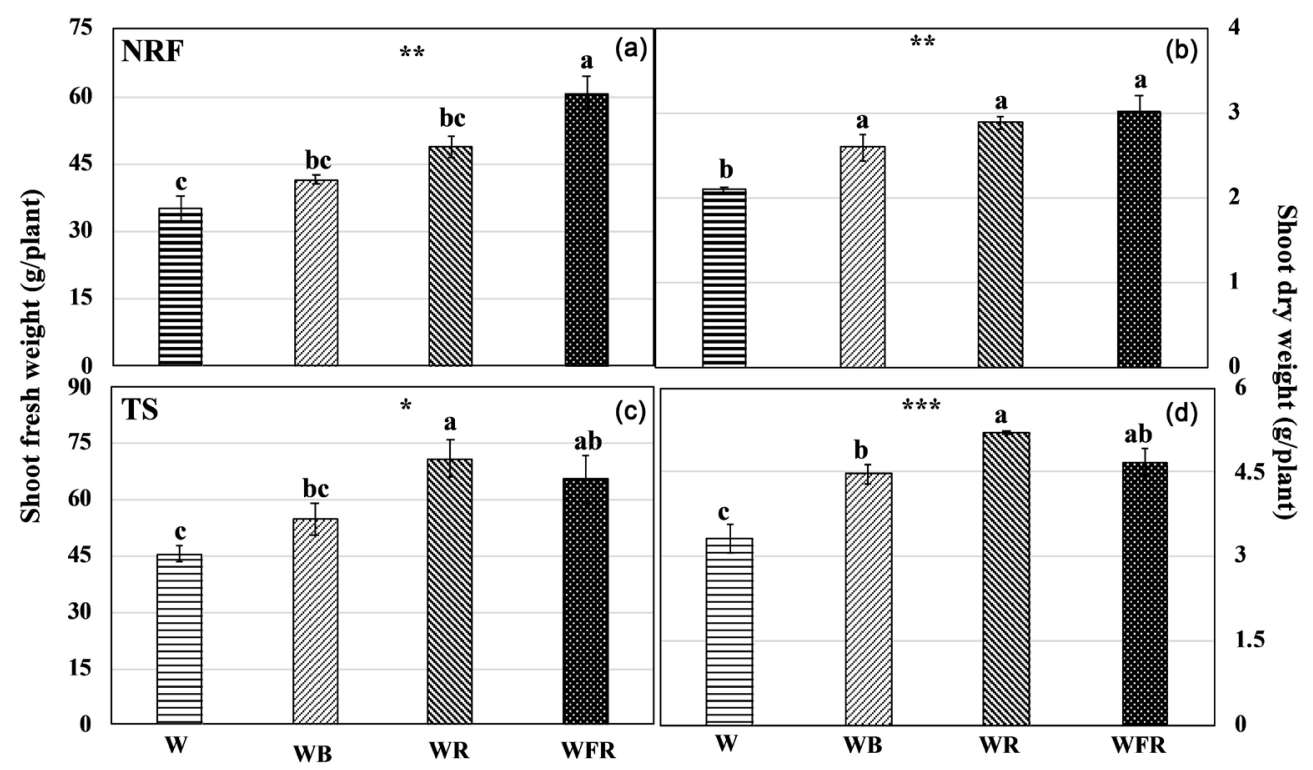

Figure 1. Shoot fresh and dry weight in lettuce red leaf variety, "New Red Fire" (NRF), and green leaf variety, "Two Star" (TS), and supplemental LED radiation. Fresh weight (a) and dry weight of shoots (b) for NRF and fresh weight (c) and dry weight of shoots (d) for TS in response to fluorescent white light (W-control) and supplemental blue (WB), red (WR) and far-red (WFR) are presented. Vertical bars indicate SD and significant differences are indicated at $\mathrm{p} \leq 0.05, \mathrm{p} \leq 0.01$ and $\mathrm{p}$ $\leq 0.001$ with $^{*},{ }^{* *}$ and ${ }^{* * *}$, respectively. 
only supplemental far-red radiation in "New Red Fire", it increased under both supplemental red and far-red radiation treatments in "Two Star" relative to the control plants. However, all supplemental radiation treatments (blue, red and far-red) increased the dry biomass in both red leaf and green leaf varieties. Addition of red and blue radiation are expected to increase the biomass as both of these are directly involved in photosynthesis in converting the radiant energy into chemical energy to be used in fixing $\mathrm{CO}_{2}$. Addition of far-red radiation may also aid in enhancing photosynthesis by perhaps increasing the plant leaf area, as we have found in this study (Figure 2). Supplemental far-red LEDs have been shown to increase fresh and dry weight, stem length and leaf area in red-leaf lettuce relative to white light [23]. With regard to the root growth, generally, "Two Star" produced larger root system than did the "New Red Fire" under control conditions (Table 1). Supplemental red radiation produced significant increases in fresh and dry root biomass in both "New Red Fire" and "Two Star," however, in addition to red radiation, supplemental blue radiation also enhanced fresh root mass in "Two Star." The fresh root biomass was approximately $40 \%$ to $59 \%$ higher due to supplemental red radiation in both varieties than that in the control plants.

While far-red light increased the shoot biomass in both varieties, it had distinct effect on the morphology of lettuce plants. It significantly reduced the number of leaves while increasing the total leaf area in both varieties (Figure 2). Supplemental far-red radiation increased the leaf area by more than $45 \%$ in both

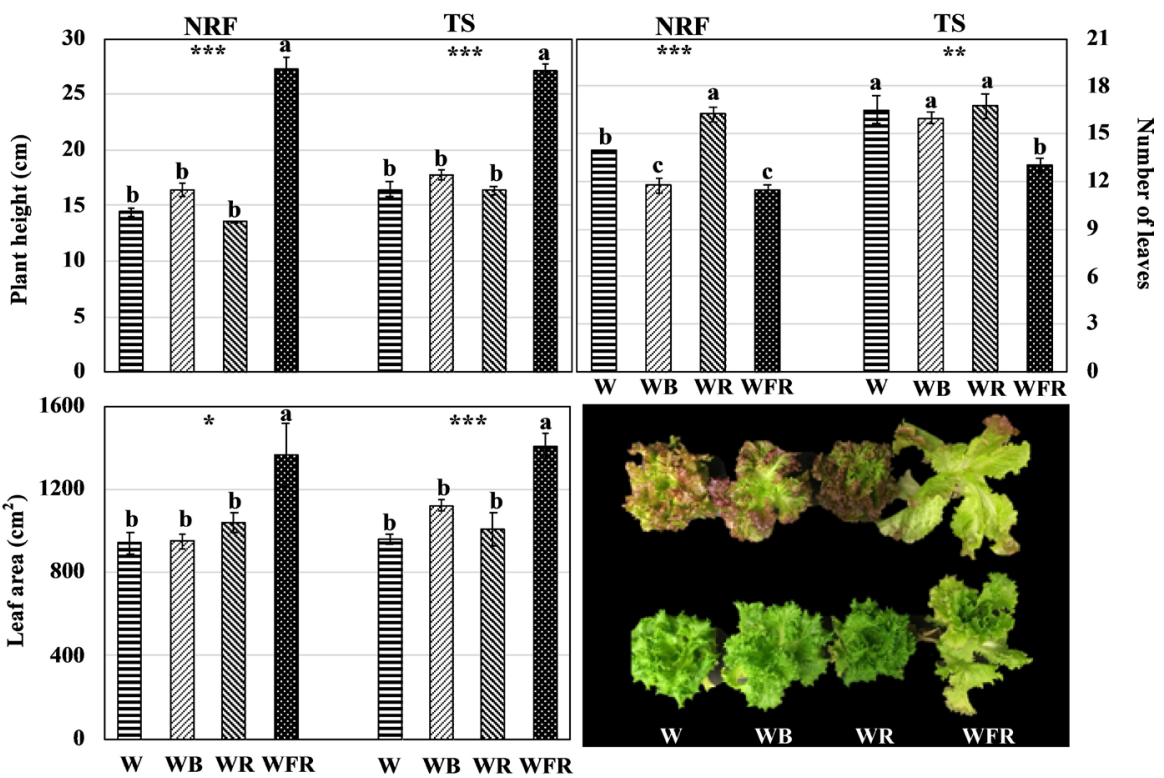

Figure 2. Growth characteristics of lettuce red leaf variety, "New Red Fire" (NRF), and green leaf variety, "Two Star" (TS) and supplemental LED radiation. Plant height, number of leaves/plant and leaf area in response to fluorescent white light (W-control) and supplemental blue (WB), red (WR) and far-red (WFR) are presented. Photograph shows plants subjected to various light treatments (top row "New Red Fire" and bottom row "Two star"). Vertical bars indicate SD and significant differences are indicated at $p \leq 0.05$, $\mathrm{p} \leq 0.01$ and $\mathrm{p} \leq 0.001$ with $^{*},{ }^{* *}$ and ${ }^{* *}$, respectively. 
Table 1. Root fresh weight (FW) and dry weight (DW) in red leaf "New Red Fire" and green leaf "Two Star" lettuce in response to supplemental blue, red and far-red radiation. Supplemental radiation was provided by LEDs against a background of white light (W). Significant differences are indicated by letters at $\mathrm{p} \leq 0.05, \mathrm{p} \leq 0.01$ and $\mathrm{p} \leq 0.001$ with , ${ }^{* *}$ and ${ }^{* * *}$, respectively.

\begin{tabular}{ccccc}
\hline & \multicolumn{2}{c}{ New Red Fire } & \multicolumn{2}{c}{ Two Star } \\
\cline { 2 - 5 } & \multicolumn{2}{c}{ Root } & Root \\
\cline { 2 - 5 } & FW (g/plant) & DW (g/plant) & FW (g/plant) & DW (g/plant) \\
W & $9197.03^{\mathrm{b}}$ & $677.50^{\mathrm{b}}$ & $12285.60^{\mathrm{b}}$ & $1023.13^{\mathrm{b}}$ \\
W-Blue & $8324.47^{\mathrm{b}}$ & $548.47^{\mathrm{b}}$ & $18131.23^{\mathrm{a}}$ & $1568.67^{\mathrm{b}}$ \\
W-Red & $13007.47^{\mathrm{a}}$ & $1021.97^{\mathrm{a}}$ & $19590.13^{\mathrm{a}}$ & $1912.43^{\mathrm{a}}$ \\
W-Far-red & $8049.63^{\mathrm{b}}$ & $596.43^{\mathrm{b}}$ & $11511.50^{\mathrm{b}}$ & $940.87^{\mathrm{b}}$ \\
Significance & $* * *$ & $* * *$ & $* *$ & $*$ \\
\hline
\end{tabular}

varieties. Plants were larger under supplemental far-red radiation compared to the control plants. Under far-red supplemental radiation, plant height increased by approximately by $89 \%$ in the case of "New Red Fire" and by more than $63 \%$ in "Two Star" (Figure 2). High proportion of far-red radiation can trigger shade avoidance characteristics which include larger leaf area, elongated petiole, low chlorophyll content and fewer leaves [16] [32]. Plants receiving far-red will have higher phytochrome Pr form than Pfr resulting in shade avoidance syndrome which is characterized by changes in the morphological characteristics. This is often observed in crowded canopies which are exposed to greater amount far-red radiation (more Pr than Pfr) than direct red radiation, thus resulting in shade avoidance characteristics [21]. Also, in our study, there was much reduced leaf coloration in "New Red Fire" under supplemental far-red radiation compared to the control plants while plants under supplemental blue produced deeper red foliage. The reduced coloration is due to lower leaf anthocyanin content when plants are exposed to far-red light [5] [23] while supplemental blue radiation has been known to increase the concentration of leaf anthocyanin content in lettuce [23]. Owens and Lopez [17] found that when red leaf varieties of lettuce were exposed to supplemental radiation of red, blue or a combination of equal ratio of red and blue for 5-7 days, there was an increase in their foliage color, which had a positive impact on their aesthetic appeal and marketability.

The response of total chlorophyll and carotenoids to specific spectra of light varied in lettuce varieties (Figure 3). In the red leaf "New Red Fire," supplemental blue and far-red exposure increased both chlorophyll and carotenoid concentrations in the leaves, in contrast both red and far-red exposure significantly reduced both chlorophyll and carotenoid concentrations in the leaves of green leaf "Two Star." Thus, the response of chlorophyll and carotenoid contents in lettuce to spectral quality of light is dependent on the variety/genotype [8]. However, the response of total chlorophyll concentration in both varieties to supplemental radiation was similar to that of chlorophyll a while there were no 
significant changes in chlorophyll b concentrations to the supplemental radiation in both varieties, suggesting that chlorophyll a is sensitive to supplemental radiation rather than chlorophyll $b$ (Table 2). In a study to examine the effect of supplemental LEDs on red leaf lettuce, Li and Kubota [23] found that supplementing white light with blue radiation increased xanthophylls and $\beta$-carotene in the leaves but not with red light while far-red light suppressed both of these carotenoids. Kopsell et al. [13] found that a combination of red and blue radiation from LEDs increased concentration of chlorophyll and carotenoids in the shoot tissue of broccoli microgreens grown under hydroponic system compared to the plants under conventional white light.

The total phenolic concentration and antioxidant capacity of leaves measured

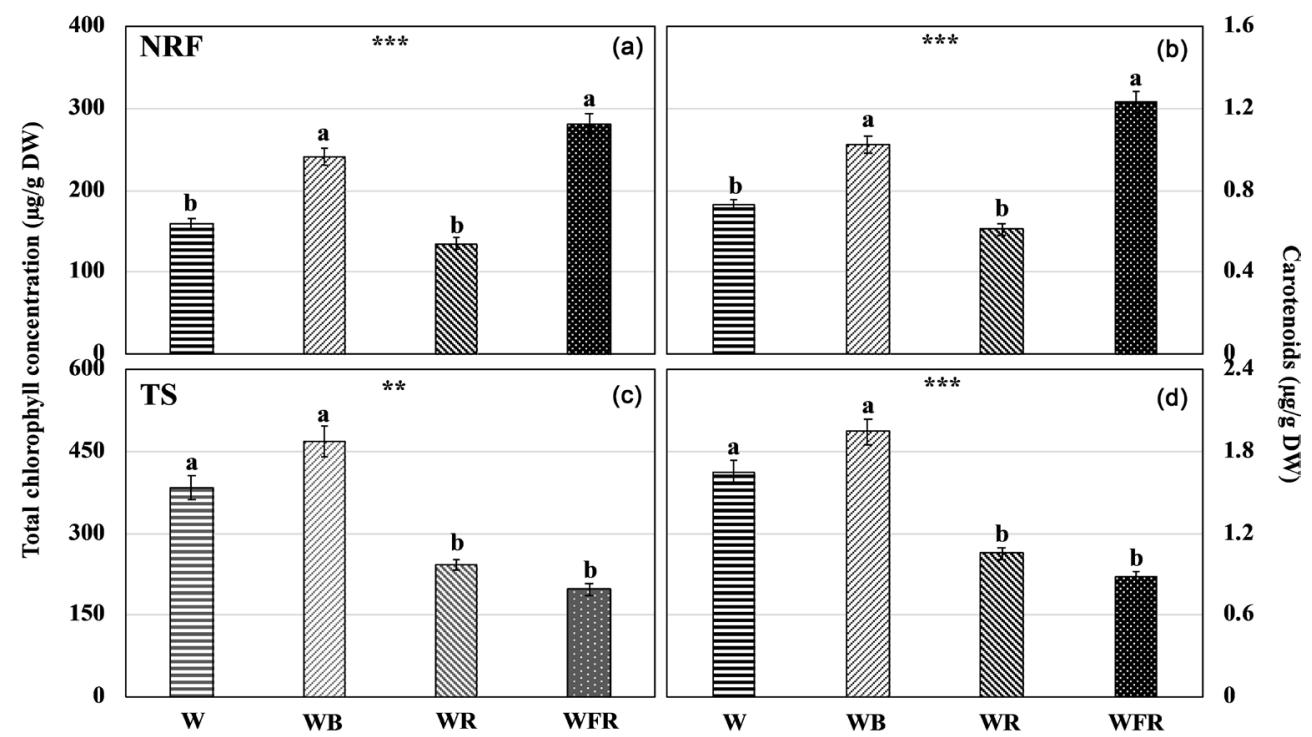

Figure 3. Chlorophyll and carotenoid concentrations in leaves of lettuce red leaf variety, "New Red Fire" (NRF), and green leaf variety, "Two Star" (TS), and supplemental LED radiation. The treatments included fluorescent white light (W-control) and supplemental blue (WB), red (WR) and far-red (WFR). Vertical bars indicate SD and significant differences are indicated at $\mathrm{p} \leq 0.01$ and $\mathrm{p}$ $\leq 0.001$ with $^{* *}$ and ${ }^{* *}$, respectively.

Table 2. Chlorophyll a and chlorophyll b concentration in leaves of red leaf "New Red Fire" and green leaf "Two Star" lettuce in response to supplemental blue, red and far-red radiation. Supplemental radiation was provided by LEDs against a background of white light. Significant differences are indicated by letters at $\mathrm{p} \leq 0.01$ and $\mathrm{p} \leq 0.001$ with ${ }^{\star *}$ and ${ }^{* *}$, respectively. NS represents no significant differences.

\begin{tabular}{ccccc}
\hline & \multicolumn{2}{c}{ New Red Fire } & \multicolumn{2}{c}{ Two Star } \\
\cline { 2 - 5 } & Chl a $(\mu \mathrm{g} / \mathrm{g}$ DW) & Chl b $(\mu \mathrm{g} / \mathrm{g}$ DW) & Chl a $(\mu \mathrm{g} / \mathrm{g}$ DW $)$ & Chl b $(\mu \mathrm{g} / \mathrm{g} \mathrm{DW})$ \\
\hline W & $121.3^{\mathrm{b}}$ & 4.35 & $298.6^{\mathrm{a}}$ & 4.17 \\
W-Blue & $188.2^{\mathrm{a}}$ & 4.16 & $363.7^{\mathrm{a}}$ & 4.21 \\
W-Red & $104.6^{\mathrm{b}}$ & 4.22 & $187.6^{\mathrm{b}}$ & 4.24 \\
W-Far-red & $217.7^{\mathrm{a}}$ & 4.29 & $152.2^{\mathrm{b}}$ & 4.24 \\
Significance & $* * *$ & $\mathrm{NS}$ & $* *$ & $\mathrm{NS}$ \\
\hline
\end{tabular}


at the time of harvest (without any supplemental light treatment) were significantly higher in red leaf "New Red Fire" compared to the green leaf "Two Star" (Figure 4). This finding is supported by previous studies that show red leaf lettuce varieties have higher concentration of many health-promoting phenolic compounds than do green leaf lettuce [33] [34]. In our study, supplemental blue radiation significantly enhanced the concentration of total phenolic content and antioxidant capacity in the leaves of both varieties (Figure 4). However, the increases were more pronounced in green leaf "Two Star" (nearly $75 \%$ over the control) compared to red leaf "New Red Fire." Similarly, studies by Stutte and Edney [35] on the effects of spectral quality of light on lettuce found an increase in antioxidant capacity by adding blue radiation to red radiation through LEDs.

We also examined the accumulation of individual phenolic compounds in the leaves of lettuce varieties as affected by supplemental radiation (Figure 5). Supplemental blue radiation in "Two Star" significantly increased the accumulation of a number of phenolic compounds including chlorogenic acid, chicoric acid, rutin, kaempferol, luteolin and apigenin (Figure 5 and Table 3). It should be noted that the supplemental blue light resulted in a strikingly large accumulation of some of the phenolic compounds. For example, while leaves of control plants of "Two Star" had very low concentration of rutin $(26.82 \mu \mathrm{g} / \mathrm{g}$ DW), exposure of plants to supplemental blue radiation resulted more than 20 -fold increase in its concentration. Similarly, the supplemental blue light increased the accumulation of apigenin and kaempferol in leaves by more than 4.5 -fold and luteolin by approximately 2.5 -fold in the leaves of "Two Star." Furthermore, exposure of "Two

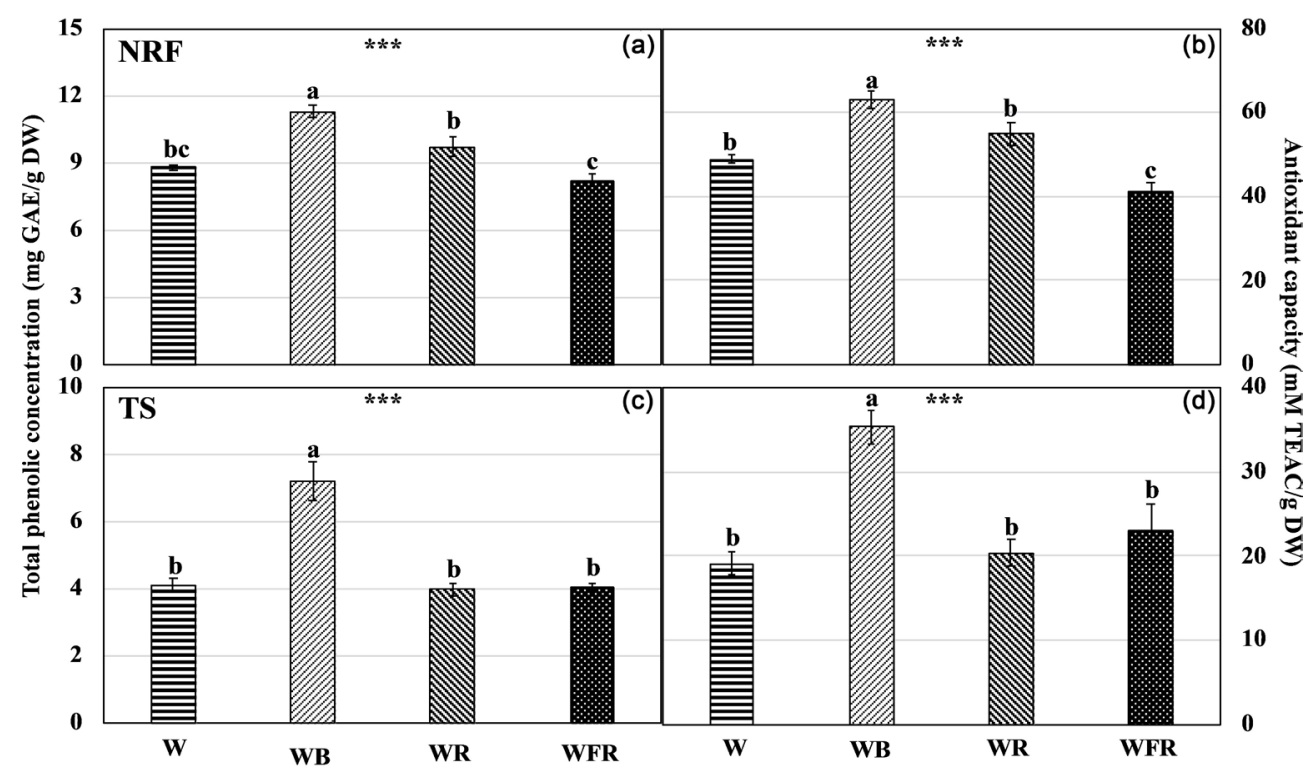

Figure 4. Total phenolic concentration and antioxidant capacity of lettuce red leaf variety, "New Red Fire" (NRF), and green leaf variety, “Two Star" (TS), and supplemental LED radiation. Total phenolic concentration and antioxidant capacity in NRF [(a) and (b), respectively] and in TS [(c) and (d), respectively] are shown. The treatments included fluorescent white light (W-control) and supplemental blue (WB), red (WR) and far-red (WFR). Vertical bars indicate SD and significant differences are indicated at $\mathrm{p} \leq 0.001$ with ${ }^{* * *}$. 


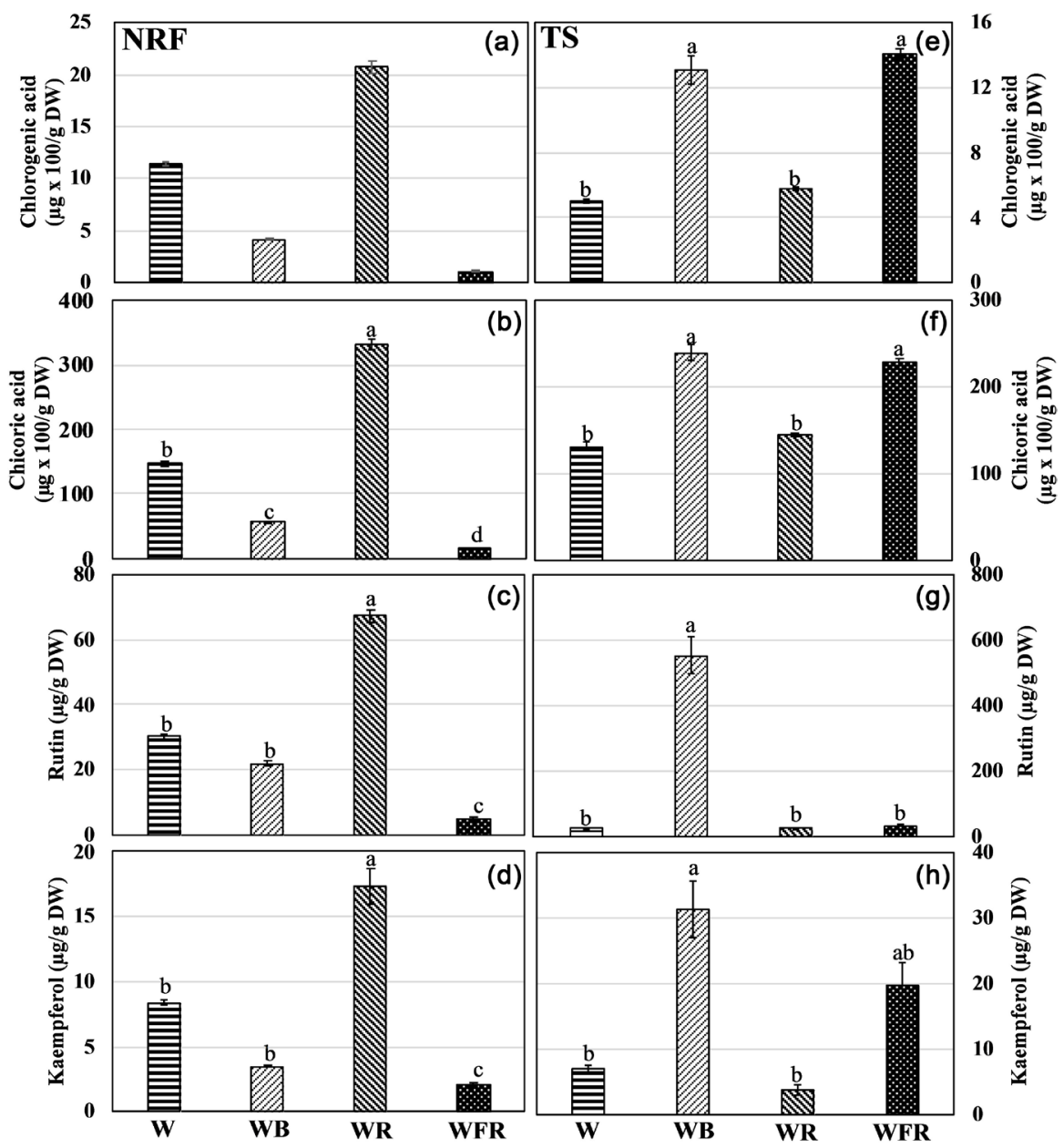

Figure 5. Concentration of phenolic compounds in lettuce red leaf variety, "New Red Fire" [NRF-(a), (b), (c) and (d)], and green leaf variety, "Two Star" [TS-(e), (f), (g) and (h)], and supplemental LED radiation. The treatments included fluorescent white light (W-control) and supplemental blue (WB), red (WR) and far-red (WFR). Vertical bars indicate $\mathrm{SD}$ and significant differences are indicated by letters at $\mathrm{p} \leq 0.05$.

Table 3. Phytochemical concentration in leaves of red leaf "New Red Fire" and green leaf "Two Star" lettuce in response to supplemental blue, red and far-red radiation. Supplemental radiation was provided by LEDs against a background of white light $(\mathrm{W})$. The values are presented with SD and significant differences are indicated by letters at $\mathrm{p} \leq 0.05$.

\begin{tabular}{|c|c|c|c|c|c|}
\hline & & \multicolumn{4}{|c|}{ Phytochemicals ( $\mu \mathrm{g} / \mathrm{g} D W)$} \\
\hline & & Gallic acid & Caffeic acid & Luteolin & Apigenin \\
\hline \multirow{4}{*}{ New Red Fire } & $\mathrm{W}$ & $85.05 \pm 8.3^{\mathrm{ab}}$ & $48.67 \pm 2.7^{\mathrm{b}}$ & $259.70 \pm 11.5^{\mathrm{b}}$ & - \\
\hline & W-Blue & $4.63 \pm 0.5^{\mathrm{b}}$ & $13.40 \pm 9.0^{c}$ & $145.62 \pm 14.2^{\mathrm{c}}$ & - \\
\hline & W-Red & $101.50 \pm 64.0^{\mathrm{a}}$ & $218.74 \pm 15.5^{\mathrm{a}}$ & $405.07 \pm 74.1^{\mathrm{a}}$ & - \\
\hline & W-Far-red & $5.13 \pm 1.8^{\mathrm{b}}$ & $4.37 \pm 1.4^{\mathrm{d}}$ & $24.89 \pm 6.4^{\mathrm{d}}$ & - \\
\hline \multirow{4}{*}{ Two Star } & $\mathrm{W}$ & $18.75 \pm 11.1^{\mathrm{ab}}$ & $100.93 \pm 13.7^{\mathrm{ab}}$ & $172.91 \pm 14.9^{c}$ & $3.92 \pm 0.04^{\mathrm{b}}$ \\
\hline & W-Blue & $27.70 \pm 16.9^{\mathrm{ab}}$ & $116.97 \pm 45.2^{\mathrm{ab}}$ & $442.28 \pm 28.1^{\mathrm{b}}$ & $19.47 \pm 4.0^{\mathrm{a}}$ \\
\hline & W-Red & $6.33 \pm 4.6^{\mathrm{b}}$ & $59.08 \pm 35.0^{\mathrm{b}}$ & $228.40 \pm 56.9^{c}$ & $1.86 \pm 0.1^{\mathrm{b}}$ \\
\hline & W-Far-red & $54.48 \pm 21.2^{\mathrm{a}}$ & $178.4 \pm 36.9^{\mathrm{a}}$ & $686.43 \pm 70.7^{\mathrm{a}}$ & $17.91 \pm 7.6^{\mathrm{a}}$ \\
\hline
\end{tabular}


Star" to supplemental far-red also had a positive impact in enhancing the accumulation of certain phenolic compounds such as chlorogenic acid, chicoric acid, luteolin and apigenin. Also, it should be noted that the increase in the accumulation of the many individual phenolic compounds in response to blue supplemental radiation in "Two Star" is consistent with its higher total phenolic concentration in the leaves (Figure 4). Blue light has been shown to increase quercetin concentration and flavonol synthase, a key enzyme in the biosynthesis of quercetin in both green leaf and red leaf varieties of lettuce [36]. In addition, blue light was also found to increase the accumulation of phenolic acids in basil and flavonoids in arugula [37]. Son and Oh [15] found that increasing blue radiation increased the total phenolic concentration, antioxidant capacity and total flavonoid concentration in both red and green leaf varieties grown under a combination red and blue LEDs.

In the case of "New Red Fire," supplemental red radiation was most effective in enhancing the accumulation of phenolic compounds including chlorogenic acid, caffeic acid, chicoric acid, rutin, kaempferol, and luteolin. Similar observations of increased concentration of total phenolic compounds and antioxidant capacity were made in red leaf lettuce with supplemental red radiation [38]. While supplemental red radiation produced positive impact on the accumulation of many phenolic compounds in "New Red Fire," supplemental far-red light drastically suppressed the accumulation of most of the phenolic compounds examined in this study. For example, the leaf concentrations of most of the phenolic compounds (caffeic acid, chlorogenic acid, chicoric acid, ruitn, kaempferol and luteolin) in "New Red Fire" grown under supplemental far-red light were much lower than those in the control plants and only ranged from $8 \%$ to $25 \%$ of the levels found in the control plants. The results show a strong inhibitory effect of far-red on the accumulation of phenolic compounds in "New Red Fire" lettuce plants.

Leaves from plants grown under supplemental lighting were analyzed for carbon, nitrogen and micronutrient composition at the time of harvest (Table 4). Generally, accumulation of most the nutrients was not affected by supplemental radiation treatments in both varieties. In the case of "New Red Fire," the accumulation of most of the micronutrients did not significantly vary with respect to different supplemental radiation treatments except for manganese which accumulated in the leaves at much higher concentrations (about 1.4-fold higher) in plants subjected supplemental red light compared to control plants. Thus, in "New Red Fire," supplemental red radiation had a positive impact not only on the accumulation of many phenolic compounds but also on the important micronutrient, manganese. However in "Two Star," all the supplemental light treatments had a negative impact on the accumulation of nitrogen and zinc compared to the control plants. In addition, carbon accumulation was also suppressed by supplemental red and far-red radiation as well. It is not clear how the spectral quality of light may influence the accumulation of nutrients in plants. 
Table 4. Leaf concentration of nutrients in red leaf "New Red Fire" and green leaf "Two Star" lettuce in response to supplemental blue, red and far-red radiation. Supplemental radiation was provided by LEDs against a background of white light (W). Significant differences are indicated by letters at $p \leq 0.05, p \leq 0.01$ and $p \leq 0.001$ with ${ }^{*}$, ${ }^{*}$ and ${ }^{* *}$, respectively. NS represents no significant differences.

\begin{tabular}{|c|c|c|c|c|c|c|c|c|c|c|c|c|}
\hline & Light source & $\mathrm{N}(\%)$ & C (\%) & $\mathrm{P}(\%)$ & K (\%) & $\mathrm{Ca}(\%)$ & $\mathrm{Mg}(\%)$ & $\mathrm{SO}_{4}-\mathrm{S}(\%)$ & $\mathrm{Cu}(\mathrm{ppm})$ & $\mathrm{Fe}(\mathrm{ppm})$ & $\mathrm{Mn}(\mathrm{ppm})$ & $\mathrm{Zn}(\mathrm{ppm})$ \\
\hline \multirow{5}{*}{$\begin{array}{c}\text { New Red } \\
\text { Fire }\end{array}$} & $\mathrm{W}$ & 2.718 & 36.42 & 0.559 & 4.87 & 0.794 & 0.316 & 0.204 & 5.10 & 109.58 & $89.78^{\mathrm{b}}$ & 49.48 \\
\hline & W-Blue & 2.565 & 36.88 & 0.566 & 4.64 & 0.783 & 0.324 & 0.245 & 4.95 & 104.53 & $96.43^{\mathrm{b}}$ & 49.65 \\
\hline & W-Red & 2.388 & 36.14 & 0.553 & 4.80 & 0.933 & 0.348 & 0.224 & 5.15 & 165.38 & $129.08^{a}$ & 52.35 \\
\hline & W-Far-red & 2.842 & 35.90 & 0.571 & 4.94 & 0.821 & 0.364 & 0.267 & 4.65 & 165.45 & $80.43^{\mathrm{b}}$ & 43.10 \\
\hline & Significance & NS & NS & NS & NS & NS & NS & NS & NS & NS & * & NS \\
\hline \multirow{5}{*}{ Two star } & W & $2.073^{\mathrm{a}}$ & $38.68^{\mathrm{a}}$ & 0.398 & 4.02 & 0.925 & 0.255 & 0.196 & 3.78 & 80.60 & 92.58 & $34.73^{\mathrm{a}}$ \\
\hline & W-Blue & $1.718^{\mathrm{b}}$ & $39.07^{\mathrm{a}}$ & 0.359 & 3.62 & 0.846 & 0.242 & 0.182 & 2.88 & 95.55 & 90.20 & $26.43^{b}$ \\
\hline & W-Red & $1.723^{\mathrm{b}}$ & $37.82^{\mathrm{b}}$ & 0.396 & 3.70 & 0.664 & 0.206 & 0.176 & 3.23 & 77.95 & 77.68 & $28.83^{\mathrm{b}}$ \\
\hline & W-Far-red & $1.738^{\mathrm{b}}$ & $37.92^{\mathrm{b}}$ & 0.351 & 3.86 & 0.859 & 0.257 & 0.180 & 3.05 & 94.63 & 92.55 & $23.45^{\mathrm{b}}$ \\
\hline & Significance & $* * *$ & $* *$ & NS & NS & NS & NS & NS & NS & NS & NS & $* *$ \\
\hline
\end{tabular}

However, in a study on broccoli sprouts, Kopsell et al. [13] reported that the blue light exposure of plants increased the concentration of a number of micronutrients including manganese. They attributed this response to the influence of blue radiation on stomatal opening, membrane permeability and other membrane properties that may impact transport of nutrients [8].

\section{Summary}

In summary, supplementing spectral quality of light has a major impact on the growth and nutritional quality of lettuce. Supplementing blue and red radiation produced large increases in many health-promoting phenolic compounds in green leaf and red leaf lettuce varieties, respectively. In addition, supplementing blue, red or far-red radiation resulted in higher shoot dry matter accumulation in both lettuce varieties. However, supplementing far-red radiation produced distinct morphological changes in both varieties such as enhanced shoot growth, increased leaf area and plant height but with reduced leaf number, similar to the shade avoidance response. Furthermore, it had an inhibitory effect on the accumulation of many phenolic compounds in red leaf variety, "New Red Fire". While supplemental radiation did not affect the accumulation of most micronutrients, it suppressed the accumulation of some micronutrients in lettuce.

\section{Acknowledgements}

We thank USDA-AFRI for providing the financial support (Grant 20166701724712) to conduct this study.

\section{Conflicts of Interest}

The authors declare no conflicts of interest regarding the publication of this paper. 


\section{References}

[1] Mancinelli, A.L. (1985) Light Dependent Anthocyanin Synthesis: A Model System for the Study of Plant Photomorphogenesis. Botanical Review, 51, 107-157. https://doi.org/10.1007/BF02861059

[2] Jenkins, G.I., Long, J.C., Wade, H.K., Shenton, M.R. and Bibikova, T.N. (2001) UV and Blue Light Signaling: Pathways Regulating Chalcone Synthase Gene Expression in Arabidopsis. New Phytology, 151, 121-131. https://doi.org/10.1046/j.1469-8137.2001.00151.x

[3] Meng, Q. and Runkle, E.S. (2018) Using Radiation to Enhance Quality Attributes of Leafy Vegetables: A Mini Review. Acta Horticulturae, 1227, 517-578. https://doi.org/10.17660/ActaHortic.2018.1227.72

[4] Olle, M. and Virsile, A. (2013) The Effects of Light-Emitting Diode Lighting on Greenhouse Plant Growth and Quality. Agricultural and Food Science, 22, 223-234. https://doi.org/10.23986/afsci.7897

[5] Stutte, G.W. (2009) Light-Emitting Diode for Manipulating the Phytochrome Apparatus. HortScience, 44, 231-234. https://doi.org/10.21273/HORTSCI.44.2.231

[6] Massa, G.D., Kim, H.H., Wheeler, R.M. and Mitchell, C.A. (2008) Plant Productivity in Response to LED Lighting. HortScience, 43, 1951-1956. https://doi.org/10.21273/HORTSCI.43.7.1951

[7] Bian, Z.H., Yang, Q.C. and Liu, W.K. (2014) Effects of Light Quality on the Accumulation of Phytochemicals in Vegetables Produced in Controlled Environments: A Review. Journal of the Science of Food and Agriculture, 95, 869-877. https://doi.org/10.1002/jsfa.6789

[8] Kospell, D.A., Sams, C.E. and Morrow, R.C. (2015) Blue Wavelengths from LED Lighting Increase Nutritionally Important Metabolites in Specialty Crops. HortScience, 50, 1285-1288. https://doi.org/10.21273/HORTSCI.50.9.1285

[9] Carvalho, S.D. and Folta, K.M. (2014) Sequential Light Programs Shape Kale (Brassica napus) Sprout Appearance and Alter Metabolic and Nutrient Content. Horticulture Research, 1, 8. https://doi.org/10.1038/hortres.2014.8

[10] Kim, H.H., Wheeler, R.M., Sager, J.C., Yorio,, N.C. and Goins, G.D. (2005) Light-Emitting Diodes as an Illumination Source for Plants: A Review of Research at Kennedy Space Center. Habitation, 10, 71-78. https://doi.org/10.3727/154296605774791232

[11] Hamm, M.R., Rider, S.D., Ogas, J., Murry, D.J. and Chapple, C. (2004) Light Induces Phenylpropanoid Metabolism in Arbidopsis Roots. The Plant Journal, 38, 765-778. https://doi.org/10.1111/j.1365-313X.2004.02089.x

[12] Bian, Z.H., Cheng, R.F., Yang, Q.C. and Wang, J. (2016) Continuous Light from Red, Blue, and Green Light Emitting Diodes Reduces Nitrate Content and Enhances Phytochemical Concentrations and Antioxidant Capacity in Lettuce. Journal of the American Society for Horticulture Science, 141, 186-195. https://doi.org/10.21273/JASHS.141.2.186

[13] Kopsell, D.A., Sams, C.E. and Barickman, T.C. (2014) Sprouting Broccoli Accumulate Higher Concentrations of Nutritional Important Metabolites under Narrow-Band Light-Emitting Diode Lighting. Journal of the American Society for Horticultural Science, 139, 4669-477. https://doi.org/10.21273/JASHS.139.4.469

[14] Craver, J.K., Gerovac, J.R. and Lopez, R.G. (2017) Light Intensity and Light Quality from Sole-Source Light Emitting Diodes Impact Phytochemical Concentrations within Brassica Microgreens. Journal of the American Society for Horticultural So- 
ciety, 142, 3-12. https://doi.org/10.21273/JASHS03830-16

[15] Son, K. and Oh, M. (2013) Leaf Shape, Growth, and Antioxidant Phenolic Compounds of Two Lettuce Cultivars Grown under Various Combinations of Blue and Red Light-Emitting Diodes. HortScience, 48, 988-995. https://doi.org/10.21273/HORTSCI.48.8.988

[16] Meng, Q., Kelly, N. and Runkle, E.S. (2019) Substituting Green or Red Radiation for Blue Radiation Induces Shade Avoidance and Promotes Growth in Lettuce and Kale. Environmental and Experimental Botany, 162, 383-391. https://doi.org/10.1016/j.envexpbot.2019.03.016

[17] Owen, W.W. and Lopez, R.G. (2015) End-of-Production Supplemental Lighting with Red and Blue Light-Emitting Diodes (LEDs) Influences Red Pigmentation of Four Lettuce Varieties. HortScience, 50, 676-684. https://doi.org/10.21273/HORTSCI.50.5.676

[18] Cashmore, A.R., Jarillo, J.A., Wu, Y.J. and Liu, D. (1999) Cryptochromes: Blue Light Receptors for Plants and Animals. Science, 284, 760-765. https://doi.org/10.1126/science.284.5415.760

[19] Briggs, W.R. and Huala, E. (1999) Blue-Light Photoreceptors in Higher Plants. Annual Review of Cell and Development Biology, 15, 33-62. https://doi.org/10.1146/annurev.cellbio.15.1.33

[20] Mathews, S. (2006) Phytochrome-Mediated Development in Land Plants: Red Light Sensing Evolves to Meet the Challenges of Changing Light Environments. Molecular Ecology, 15, 3483-3503. https://doi.org/10.1111/j.1365-294X.2006.03051.x

[21] Franklin, K.A. and Whitelam, G.C. (2005) Phytochromes and Shade-Avoidance Responses in Plants. Annals of Botany, 96, 169-175. https://doi.org/10.1093/aob/mcil65

[22] Devlin, P.F. (2016) Plants Wait for the Light to Change to Red. Proceedings of the National Academy of Sciences USA, 113, 7301-7303.

https://doi.org/10.1073/pnas.1608237113

[23] Li, Q. and Kubota, C. (2009) Effects of Supplemental Light Quality on Growth and Phytochemicals of Baby Leaf Lettuce. Environmental and Experimental Botany, 67, 59-64. https://doi.org/10.1016/j.envexpbot.2009.06.011

[24] Yu, X., Liu, H., Klejont, J. and Lin, C. (2010) The Cryptochrome Blue Light Receptors. The Arabidopsis Book, 8, e0135. https://doi.org/10.1199/tab.0135

[25] Lin, C. (2002) Blue Light Receptors and Signal Transduction. The Plant Cell, 14, S207-S225. https://doi.org/10.1105/tpc.000646

[26] Oh, O., Carey, E.E. and Rajashekar, C.B. (2009) Environmental Stresses Induce Health-Promoting Phytochemicals in Lettuce. Plant Physiology and Biochemistry, 47, 578-583. https://doi.org/10.1016/j.plaphy.2009.02.008

[27] Chen, X., Wang, L., Li, T., Yang, Q. and Guo, W. (2019) Sugar Accumulation and Growth of Lettuce Exposed to Different Lighting of Red and Blue LED Light. Scientific Reports, 9, Article No. 6926. https://doi.org/10.1038/s41598-019-43498-8

[28] Ainsworth, E.A. and Gillespie, K.M. (2007) Estimation of Total Phenolic Content and Other Oxidation Substrates in Plant Tissues Using Folin-Ciocalteu Reagent. Nature Protocols, 2, 875-877. https://doi.org/10.1038/nprot.2007.102

[29] Miller, N.J. and Rice-Evans, C.A. (1996) Spectrophotometric Determination of Antioxidant Activity. Redox Report, 2, 161-171.

https://doi.org/10.1080/13510002.1996.11747044

[30] Pennycooke, J.C., Cox and Stushnoff, C. (2005) Relationship of Cold Acclimation, 
Total Phenolic Content and Antioxidant Capacity with Chilling Tolerance in Petunia (Petunia x hybrida). Environmental and Experimental Botany, 53, 225-232. https://doi.org/10.1016/j.envexpbot.2004.04.002

[31] Woolley, A., Sumpter, S., Lee, M., Xu, J., Barry, S., Wang, W. and Rajashekar, C.B. (2019) Accumulation of Mineral Nutrients and Phytochemicals in Lettuce and Tomato Grown in High Tunnel and Open Field. American Journal of Plant Sciences, 10, 125-138. https://doi.org/10.4236/ajps.2019.101011

[32] McLaren, J.S. and Smith, H. (1978) Phytochrome Control of the Growth and Development of Rumex obtusifolius under Simulated Canopy Light Environments. Plant, Cell and Environment, 1, 61-67. https://doi.org/10.1111/j.1365-3040.1978.tb00748.x

[33] Zhao, X., Carey, E.E., Young, J.E., Wang, W. and Iwamoto, T. (2007) Influences of Organic Fertilization, High Tunnel Environment, and Postharvest Storage on Phenolic Compounds. HortScience, 42, 71-76.

https://doi.org/10.21273/HORTSCI.42.1.71

[34] Oh, M., Carey, E.E. and Rajashekar, C.B. (2011) Antioxidant Phytochemicals in Lettuce Grown in High Tunnels and Open Field. Horticulture, Environment, and Biotechnology, 52, 133-139. https://doi.org/10.1007/s13580-011-0200-y

[35] Stutte, G.W., Edney, S. and Skerritt, T. (2009) Photoregulation of Bioprotectant Content of Red Leaf Lettuce with Light Emitting Diode. HortScience, 44, 79-82. https://doi.org/10.21273/HORTSCI.44.1.79

[36] Ebisawa, M., Shoji, K., Kato, M., Shimomura, K., Goto, F. and Yoshihara, T. (2008) Supplementary Ultraviolet Radiation B Together with Blue Light at Night Increased Quercetin Content and Flavonol Synthase Gene Expression in Leaf Lettuce (Lactuca sativa L.). Environmental Control in Biology, 46, 1-11. https://doi.org/10.2525/ecb.46.1

[37] Taulavouri, K., Pyysalo, A., Taulavouri, E. and Julkunen-Tiitto (2018) Responses of Phenolic Acid and Flavonoid Synthesis to Blue and Blue-Violet Light Depends on Plant Species. Environmental and Experimental Botany, 150, 183-187. https://doi.org/10.1016/j.envexpbot.2018.03.016

[38] Samuoliene, G., Brazaityte, A., Sirtatautas, R., Novickovas, A. and Duchovskis, P. (2011) Supplementary Red-LED Lighting Affects Phytochemicals and Nitrate of Baby Lettuce. Journal of Food, Agriculture \& Environment, 9, 271-274. 